\title{
The evaluation of the National Learning Network
}

\author{
Andrew S. Thomas Caven-Atack \\ School of Computing and Management Sciences, Sheffield Hallam University \\ email: a.caven-atack@shu.ac.uk
}

In December 1998, the Department for Education and Employment announced that $£ 74$ million would be made available, over a three-year period, to fund improvements in information and learning technology within English further education: this initiative is known as the National Learning Network. An evaluation team has been appointed to report.on whether the investment is being used nationally and locally in an efficient and effective manner. This paper outlines the process by which this task is being fulfilled and how the impact of the investment is being evaluated through the close monitoring of forty-one representative English $F E$ colleges. It also presents a range of free-standing evaluation tools which have been developed by the evaluation team for use within these colleges by internal practitioner-evaluators. These tools will enable colleges to assess the effectiveness of the investment and enable the evaluation team to monitor the impact of the national investment on a small, representative cohort of students and staff over a twoyear period. The paper concludes with a brief look at the role this development is playing in designing a universally applicable model for assessing cost-effectiveness across all educational sectors.

\section{Introduction}

The National Learning Network (NLN) is part of a response to the expectation that the further education (FE) sector within England will grow steadily over the next three years to fulfil the Department for Employment and Education's requirement to widen participation in this area of education. The NLN is just one of the initiatives aimed at (though not exclusive to) new students from non-traditional, disadvantaged and previously excluded groups, and is expected to bring the student population in FE to over four million. The Further Education Funding Council (FEFC) has noted that traditional FE learning paradigms are not suitable for this level of participation and that increased levels of 
information and learning technology (ILT) will need to be implemented to cope with these increased student numbers.

Because ILT is characterized by higher initial, fixed costs than traditional teaching and learning methods but has the advantage of lower variable running costs (Vries and Hertogenbosch, 1999), the majority of any ILT investment will be spent on initial fixed costs. Once these initial costs have been met, ILT should have a lower cost per student learning hour than traditional teaching and learning - providing the proper infrastructure has been put in place. This emphasis on initial fixed costs leads to a greater need for careful planning and implementation of the initial investment in ILT.

\section{The National Learning Network}

In December 1998, the Department for Education and Employment (DFEE) announced that $£ 74$ million would be made available, over a three-year period, to fund information technology (IT) infrastructure changes within English FE (FEFC, 1999a). This investment is expected to stimulate change mostly in the three main FEFC focus areas of widening participation, retention and achievement (FEFC, 1999b; FEFC, undated). On a smaller scale, this investment is expected to improve the quality of both the learning experience and the teaching experience, for both students and staff. The funding is expected to ensure that all colleges are suitably equipped to cater for both the expected increases in the student population and the changing demands of educating these students for the information society: 'If all staff and students engage IT as a normal everyday tool for teaching and learning activities, information literacy will be a natural by-product' (FEFC, 1999c).

According to the FEFC, the English FE sector currently spends around $£ 100$ million per annum on ILT (FEFC, 1999d). The High Level Action Plan (HLAP) assumes that ILT expenditure by colleges will continue at this level and that the extra funding from the NLN will provide 'additionality' (ibid.).

Although the FE sector already invests heavily in IT, the most recent British Educational Communications and Technology agency (Becta) survey indicates that a considerable amount of this provision is out of date and incapable of meeting the current demand from students in terms of both hardware and software (Becta, 1999). Prior to the NLN, there has not been a national programme in FE to parallel higher education's Teaching and Learning Technology Programme (TLTP), which has invested some $£ 50$ million in learning content creation and related support activities since 1992 (FEFC, 1999c). However, a number of initiatives for the promotion of ILT in FE have been funded and, on the whole, have proved very successful. For example, the FEFC allocated $£ 1.9$ million over five years, starting in 1996, to fund Quality in Information and Learning Technology (QUILT), a programme of staff development for ILT use (see: http://www.feda.ac.uk/quilt/). In addition, $£ 0.575$ million was provided over a period of two years to Further Education Resources for Learning (FERL) for supporting colleges in their growing use of ILT (see: http:/lferl.becta.org.uk).

The QUILT and FERL college-based projects have achieved levels of success beyond their relatively modest investment (FEDA, 2000). However, because they were often developed in isolation, the specific models they provide cannot easily be copied by colleges in different circumstances - that is, they lack 'transferability'. What is required is a quality-assured 
evaluation process that produces examples of best practice that can be transferred to improve other situations. Such examples must be easy to understand and to implement, and for this to occur, the evaluation methodology must be transparent and easy to use. If these aims are achieved, identifying which activities to replicate, then constructing a new model by copying other models of best practice will not be a time-consuming process.

\section{Evaluating the National Learning Network}

An NLN evaluation (NLN-e) team has been appointed on behalf of the Further Education Development Agency (FEDA) to report on what ILT is being used in colleges and how this use is affecting the work of the sector. The specific aims of the NLN-e are threefold:

- to measure and identify changes in sector investment in and use of ILT over three years;

- to report changes in various sector performance indicators over the same period and link these to the application of ILT; and

- to assess changes in teaching and learning styles and methods involving the use of ILT.

The first NLN-e report to the Further Education Information and Learning Technology (FE ILT) committee (FEILTC) provides a comprehensive picture of ILT investment and effectiveness prior to the introduction of the NLN (FEDA, 2000). The report provides the basis from which sectoral change during the period of investment can be measured, assessed and compared. It includes a summary of the 1999 Becta survey, excerpts from selected FERL and QUILT case studies, a number of evaluation frameworks, and a discussion of extrinsic and intrinsic performance indicators. (Extrinsic performance indicators are directly measurable in line with the three government objectives of widening participation, increasing retention and improving achievement; intrinsic performance indicators are directly connected to ILT, such as student and staff computer ratios.) A series of performance indicators are being used as benchmarks against which future figures will be compared.

On a national level, the NLN-e involves formative (ongoing) and summative (end-ofproject) evaluation. The NLN-e team is keeping abreast of national-level NLN activities in order to assess if any of these activities have a direct impact within the case study colleges, and the NLN-e will conclude with a summative evaluation of these national-level activities.

\section{The National Learning Network Evaluation}

To assess the impact of the NLN investment at a local level, fifty carefully selected English FE colleges were offered the opportunity to participate in the NLN-e case studies; of which forty-one are now involved. Colleges were selected primarily by type - specialist, sixth form and general FE - with numbers for each type kept proportionate to the total in the sector. Colleges were grouped by size to ensure an even mix of small, medium and large institutions; they are representative by FEFC regions; and colleges on the Council's exceptional support list (colleges at risk) were excluded. In addition, it was ensured that the proportion of non-respondents to the 1999 Becta survey was similar to that for all colleges. Within these constraints, as far as possible, a balance between regions and between colleges with high and low widening participation factors was maintained. 
Each selected college was asked to choose a cohort of staff or students to study. At an induction seminar attended by representatives from participating colleges and the NLN-e team, a group of FEFC statisticians ensured that these cohorts covered a range of programme areas, age groups and modes of attendance (full-time or part-time).

\begin{tabular}{lcccc}
\hline Programme area & $\begin{array}{c}\text { Full-time } \\
\text { students } \\
\text { aged } \\
16-19\end{array}$ & $\begin{array}{c}\text { Full-time } \\
\text { students } \\
\text { aged } \\
19+\end{array}$ & $\begin{array}{c}\text { Part-time } \\
\text { students } \\
\text { aged } \\
16-19\end{array}$ & $\begin{array}{c}\text { Part-time } \\
\text { students } \\
\text { aged } \\
19+\end{array}$ \\
\hline 1 Science & 4 & & & \\
2 Agriculture & 2 & & 1 & \\
3 Construction & 1 & & 1 & 1 \\
4 Engineering & 2 & & & 1 \\
5 Business & 3 & & & 1 \\
6 Hotel \& Catering & 2 & & & 1 \\
7 Health \& Community Care & 3 & 2 & & 1 \\
8 Art \& Design & 1 & 1 & & 1 \\
9. Humanities & 6 & 1 & & 1 \\
10 Basic Education & 1 & & & \\
\hline
\end{tabular}

Table 1: Cohorts being studied within each FEFC programme area, across age ranges and modes of attendance. (One cohort is across college and age.)

The NLN-e draws upon the successes of QUILT initiatives and FERL research and development projects. These individual pieces of work have been used as examples of ideas to be copied and as mistakes to avoid (however, it must be remembered that they are used with caution because they relate to specific studies using models that are not readily transferable to other situations). For example, the case studies highlighted the close relationship between positive attitudes towards ILT and high levels of performance using ILT. Armed with this knowledge, the NLN-e team is focusing upon this relationship by including questions about attitudes and abilities in the NLN-e questionnaire analysis pack, and by requesting information about this relationship in the six-monthly NLN-e case study reports completed by participating colleges. Furthermore, questions about this relationship in the Becta survey allow the evaluation team to compare local data obtained through NLN-e case study reports compiled by colleges, with national data obtained from the Becta survey.

\section{The National Learning Network Evaluation tool pack}

The college cohorts have each been given a range of free-standing evaluation tools, collected together into an NLN-e tool pack. These tools will enable colleges to assess the effectiveness of their investment, and enable the NLN-e team to monitor the impact of the national investment on a small, representative cohort of students and staff over a two-year period. Results from these grass-roots evaluations will be combined and compared with data on national activities, taken from annual Becta surveys and from the formative evaluation reports of national activities also included under the umbrella of the NLN. 
In the tool pack, participating colleges have been provided with a number of evaluation tools to enable the collection and dissemination of a wealth of data. Colleges have been asked to collect data using 'narratives' and questionnaires, then convert collected raw data into a case study report to the NLN-e team. The NLN-e team analyses all the case study reports, then provides suitable feedback to each college and applies suggested modifications to the evaluation tools. Figure 1 provides a visual representation of this procedure.

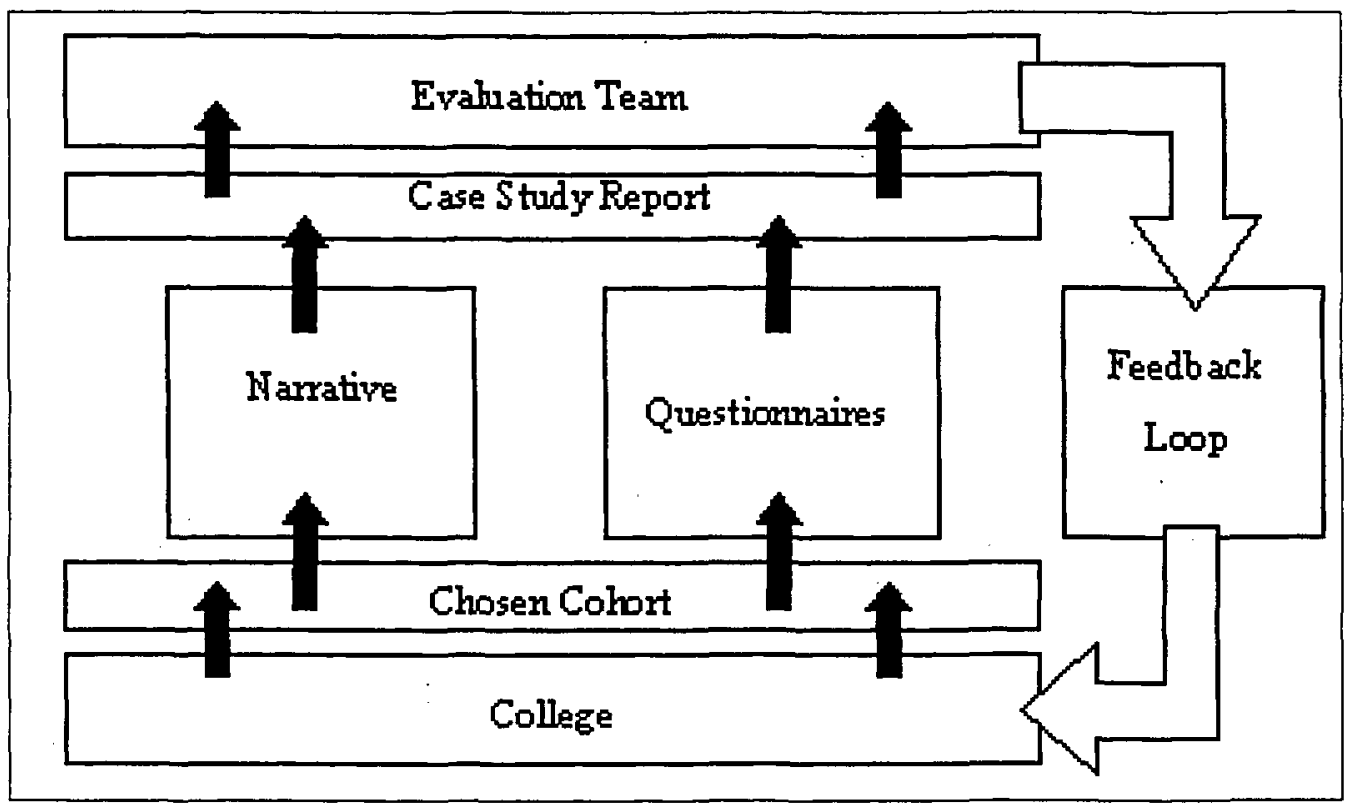

Figure 1: The evaluation process.

The first draft of the NLN-e tool pack was used to provide a snapshot of ILT spending within the selected English FE colleges. It contained three sections: narrative suggestions; questionnaires; and the reporting structure (case study format and guidelines). Each section contained guidelines for use, an evaluation tool, plus guidelines for analysis (where applicable). As it is hoped that these evaluation tools will be developed to enable colleges to perform their own evaluations in future, each tool was chosen for its ease of use and interpretation, and for its usability by non-specialists. The tool pack is aimed at FE practitioners - predominantly teachers - as it is these practitioners (not research evaluation experts) who are involved in the evaluation process as both evaluators and the subjects of the evaluation.

To appeal to all practitioners, the tool pack must cater for a wide range of individuals including ILT enthusiasts and reluctant participants, IT experts and IT novices, and IT enthusiasts and technophobes. Although targeting one group - namely, IT experts - would considerably simplify the evaluation process, targeting a wider audience will aid the holistic nature of the NLN-e and any tools that arise from the NLN-e. The NLN-e team has also benefited from having a large, representative group in terms of feedback on the NLN-e tools: thus the tool pack is modified by a representative group from colleges across the country. The lengthy duration of the evaluation is another benefit and has allowed the 
NLN-e team gradually to introduce the colleges to evaluation tools, enabling close monitoring of problems with individual aspects of each tool. This also extends the duration during which feedback is received, so the NLN-e team is not restricted to a snapshot of opinions but is treated to ongoing commentary.

The NLN-e tool pack is being developed into a framework for evaluating effectiveness that will be applicable to a variety of educational settings. At the close of the NLN-e, these developments will be disseminated to inform the debate on the cost-effectiveness of educational technologies; resulting in a set of tools for evaluating ILT developments that are applicable at an everyday level, and are available to the whole FE sector. On a larger scale, it is hoped that these tools will aid the development of an evaluation framework to assess the cost-effectiveness of learning in other sectors and on an international level.

\section{Narrative}

The flexible nature of the NLN-e tool pack means it does not impose a rigid methodology that might prove impractical in the everyday college situations for which it is intended. For example, the narrative section within the first draft suggests a number of methods that could be used to collect anecdotal information for inclusion in each case study report but none of these methods are compulsory. Individuals are encouraged to decide which method (or methods) to use, providing they let the evaluation team know how data was collected and include details of any problems and successes encountered. This should enable the NLN-e team to decide which methods are most appropriate to which situations and offer more detailed guidance in subsequent drafts of the NLN-e tool pack.

This active-reactive-adaptive approach (Patton, 1997) follows the advice proffered by a FEDA report on a questionnaire-based study, which concluded that evaluators, 'may ... . wish to consider adopting other methods of data collection as well as the questionnaire templates provided' (Attewell, Barnard and Thompson, 2000). The FEDA study also noted that, 'using questionnaires only might result in too much concentration on the product rather than the process of learning with ICT' (Attewell et al.) and went on to suggest that this problem could be overcome by combining several methods of data collection - what the NLN-e refers to as the narrative methods.

The NLN narrative methods currently being trialled in the NLN-e are listed below.

- Retrospective thinking - remembering as much as possible whilst filling in the case study report. This is the simplest and least time-consuming method, which is also highly unreliable.

- Keeping a journal - this can be time-consuming depending on how much detail is kept but it often gives a very accurate picture of what has happened and of the general response to what happened.

- Using a tape recorder - recording personal thoughts or the comments of the staff and students participating in the study onto audio cassette. This method involves a considerable amount of time and effort.

- Creating video clips or photographs - recording the cohort in action creates very rich data that can be used to provide illustrative examples. Providing a note is kept of what is being recorded, this is an innovative way of keeping track of events. 
- Group discussion - discussion between staff and students involved in the cohort can emphasize key areas to be highlighted in the case study report.

- Observation - a very rich data collection method that can be very time-consuming if detailed.

\section{Questionnaires}

The first draft of the evaluation questionnaires was adapted from work recently completed by the Open University (OU) for the FEDA (Attewell, Barnard and Thompson, 2000). Drawing upon previous research and practical experience, a set of three customizable questionnaire templates were developed and trialled. These were designed for the local evaluation of individual projects, strategies or specific uses of IT in teaching and learning. The NLN-e team refined these questionnaires for use by the NLN-e case study colleges. In doing so, the recommendations for improvements provided by FEDA were incorporated into the questionnaire design. For example, supplementing questionnaires with other data collection methods addresses the lack of triangulation in the original questionnaires. However, as with the FEDA study, questionnaires are retained by the NLN-e team as the main data collection method.

The NLN-e team sought to widen the scope of the original questionnaires to survey attitudes, to include resource evaluation and to examine costs and cost-effectiveness something beyond the remit of the original study. As the previous FEDA case study college representatives were all fairly competent and enthusiastic ILT users, it was felt that the original questionnaires might prove inappropriate for the wide range of individuals being studied by the NLN-e, especially as even these ILT enthusiasts experienced problems and misunderstandings! The NLN-e team therefore sought to simplify the FEDA questionnaire by removing the complex customization stage. Eliminating customization has the added advantages of heightening the transferability of any results obtained and also shortening the length of time needed to evaluate them. Using electronic rather than paper-based tools has also shortened the evaluation time, and this will decrease further once these tools are placed online.

To aid the analysis of these questionnaires, they were inserted into a questionnaire analysis pack, containing the three questionnaires plus guidelines for extracting meaningful data from each questionnaire. The original intention was simply to include an analysis template (as used in the FEDA precursor) along with the questionnaires, but comments from the NLN case study colleges indicated that a more structured approach would be welcomed. The main focus of the questionnaire analysis pack is on attitudes towards and competence in using ILT. Questions address the relationship between members of the chosen cohort and ILT: focusing on the availability and use of IT hardware and software; on IT skills; on attitudes towards IT; and on considerations of cost and time. The results from these questionnaires are included as an appendix to the case study reports submitted by the colleges and they provide a rich source of information to feed into each case study report.

\section{Case study report}

The case study report provides the interface between the college and the evaluation team. Each college is required to submit a report to the NLN evaluation team every six months. Once submitted, these reports are analysed and appropriate feedback is given to each college. Modification and additions to the format of the case study report are expected at 
each feedback stage. It is hoped that changes based on the reports will improve the evaluation tools and the reporting structure.

Previous FEDA case studies revealed the usefulness of having clearly defined aims at the beginning of the study (Attewell et al., 2000). For this reason, the NLN case study report format begins by asking colleges to state their aims, their progress towards meeting these aims, anything preventing their aims being achieved, and how they might overcome these barriers. In accordance with suggestions made by the FEDA, the NLN-e is an ongoing process of evaluation with colleges asked to submit regular reports. The first case study report detailed the current state of ILT within the college; subsequent reports will show changes in the use of ILT, and the NLN-e team will assess the extent to which the NLN is responsible for these changes. At the macro level of evaluation, a standard format means that colleges and their use of ILT can be easily compared with one another through the case study reports. It also provides examples of best practice, which enables practitioners at other colleges to construct their own project models by picking and choosing initiatives outlined in different reports that might be applicable to their own institution, and to assess how effective these different methods might be.

The case study report is divided into the following sections.

- General information - colleges are asked to list specific aims of using ILT with the cohort, rate how well these aims have been achieved, give reasons for these ratings and indicate what improvements might correct unsatisfactory ratings.

- About your college and cohort - colleges are asked to provide background information about the college, focusing upon ILT initiatives; colleges are also asked to provide background information about the chosen cohort as it was before the introduction of the NLN.

- Your activities to date - colleges are asked to describe current ILT initiatives, achievements and evaluations.

- What effect has the activity had? - colleges are asked to describe the impact of the activity on staff and student skills and attitudes.

- The success of the activity - colleges are asked to provide information about successes and failures.

- Comments on the evaluation tools - colleges are asked for feedback on the evaluation process.

To ensure that the format in which the evaluation data is returned to the NLN-e team remains consistent throughout all colleges, guidelines for each section of the case study report were also included in the NLN-e tool pack.

There is a subtle but fundamental difference in approach between the FEDA case studies and the NLN-e: the FEDA team favoured customization whereas the NLN-e team favours targeting the questionnaires. Individual customization does inhibit comparisons between projects and therefore reduces transferability; however, Patton (1997) does warn us to 'beware the evaluator who offers essentially the same design for every evaluation' because a universal approach would provide meaningless results with little or no practical 
application. The Learning Technology Dissemination Initiative (LTDI) Evaluation Cookbook (Harvey, 1998) provides numerous approaches to evaluation and warns that differing situations or problems demand different approaches. In response to this conundrum, Ash (2000) has called for 'a rigorous, quality assured framework that encompasses a number of different evaluative approaches', and suggests that these approaches should be selected for their suitability to the task and situation, and that they should be able to operate on a number of different levels.

\section{Conclusion}

The NLN-e continues until March 2002, when the final NLN-e report on the college case studies will be published. A collection of case study reports completed by colleges will also be made public at this time. The finalized NLN-e tool pack will be published and, it is hoped, adopted by the English FE sector for which it is being developed. The NLN-e team also intends to develop this tool pack to be applicable to a wider group of users, including users within the higher education sector.

NLN funding has enabled FE to participate in Joint Information Systems Committee (JISC) initiatives, and JISC are consequently now offering the same services to FE that have previously only been available to HE. For example, HE practitioners take high-speed Internet connections for granted but very few FE colleges are currently connected to the Joint Academic Network (JANET). By the close of the NLN, all English FE colleges will have a JANET connection. All the initiatives within the NLN are self-evaluating and are being assessed separately for their impact upon the FE sector. The self-evaluation of the JANET initiative within FE will deem the project successful if all connections work properly and are installed according to schedule; but this is not a measure of their effectiveness. The NLN-e team will assess the impact of JANET and similar initiatives, focusing upon changes within the case study colleges.

The merging of HE and FE sectors is also taking place within other initiatives, such as the University for Industry, where FE and HE are working together towards common goals. This holistic approach is also being applied to evaluation, with JISC recognizing the importance of costing alongside evaluation - for example, through the funding of the Costs of Networked Learning (CNL) project (Bacsich, Ash, Boniwell, Kaplan, Mardell and Caven-Atack, 1999). A recent FEDA report (FEDA, 2000) has already noted that costing and effectiveness are interconnected. By combining insights into the evaluation of FE gained by the NLN with knowledge about costing HE gained by the CNL project, it seems likely that a comprehensive methodology for assessing cost-effectiveness for both $\mathrm{HE}$ and FE could soon be a reality. Further information about the NLN-e is available online at: http:I/www.shu.ac.uk/nln/.

\section{Acknowledgements}

The views expressed in this paper are those of the author, who would like to acknowledge the support of Charlotte Ash at Sheffield Hallam University and Kevin Donovan at the Further Education Development Agency. 


\section{References}

Ash, C. (2000), 'Towards a new cost-aware evaluation framework', Educational Technology and Society, 3 (4), http://ifets.ieee.org/periodicallvol_4_2000/v_4_2000.html.

Attewell, J., Barnard, J. and Thompson, J. (2000), Evaluating ICT Projects and Strategies in Teaching and Learning, London: FEDA.

Bacsich, P., Ash, C., Boniwell, K., Kaplan, L., Mardell, J. and Caven-Atack, A. (1999), The Costs of Networked Learning, Sheffield: Sheffield Hallam University.

Becta (April 1999), Survey into Information and Learning Technology Provision, Access and Policy in FE Colleges in England: Report to the Further Education ILT Committee, Coventry: FEFC.

FEDA (January 2000), Making IT Happen: The First Report on the Efficiency and Effectiveness of ILT Investment in Further Education, London: FEDA.

FEFC (undated), Widening Participation in Further Education: Statistical Evidence 1996-97, Coventry: FEFC, http://www.fefc.ac.uk/documents/othercouncilpublications/ other_pdflwp_se.pdf.

FEFC (October 1999a), Networking Lifelong Learning: Making IT Happen, Coventry: FEFC.

FEFC (September 1999b), Benchmarking Data 1995-96 to 1997-98: Retention and Achievement Rates in Further Education Colleges in England, Coventry: FEFC.

FEFC (April 1999c), Networking Lifelong Learning: An ILT Development Strategy for FE, Coventry: FEFC.

FEFC (June 1999d), Networking Lifelong Learning: High-level Action Plan (HLAP), Coventry: FEFC.

FE ILT Committee (December 1999), Networking Lifelong Learning: Making IT Happen: Evaluation Strategy, London: FE ILT Committee.

Harvey, J. (ed.) (1998), The Evaluation Cookbook, Edinburgh: LTDI.

Patton, M. Q. (1997), Utilization Focused Evaluation - New Century Text, California: Sage Publications.

Vries, P. and Hertogenbosch, S. (1999), Telelearn Project Report, Netherlands: CINOP. 